\title{
Systemic Activation of Defensive Enzymes and Protection in Tobacco Plantlets against Phytophthora nicotianae Induced by Oligosaccharins
}

\author{
Alejandro Bernardo Falcón-Rodríguez¹, Daimy Costales', Juan Carlos Cabrera², \\ Ruddy Wattiez ${ }^{3}$, Miguel Ángel Martínez-Téllez ${ }^{4}$ \\ ${ }^{1}$ Group of Bioactive Products, Department of Plant Physiology and Biochemistry, National Institute of \\ Agricultural Science, Mayabeque, Cuba \\ ${ }^{2}$ Unit of Biotechnology, Materia-Nova, Ghislenghiem, Belgium \\ ${ }^{3}$ Institute of Biosciences, University of Mons, Mons, Belgium \\ ${ }^{4}$ Center for Food Research and Development (CIAD), Coordination of Technology of Foods from Plant Origin, \\ Hermosillo, Mexico \\ Email: alfalcon@inca.edu.cu, daimy@inca.edu.cu, cabrerapino@gmail.com, ruddy.wattiez@umons.ac.be, \\ norawa@ciad.mx
}

Received 1 August 2014; revised 19 September 2014; accepted 24 October 2014

Copyright (C) 2014 by authors and Scientific Research Publishing Inc.

This work is licensed under the Creative Commons Attribution International License (CC BY).

http://creativecommons.org/licenses/by/4.0/

c) (i) Open Access

\section{Abstract}

Oligosaccharins are potent biomolecules which activate defense responses and resistance in tobacco plants. However, it is not known the systemic behavior of defensive enzymes activated by these elicitors. In this work, the dynamic behavior of key defensive enzymes was evaluated in tobacco plant leaves previously treated through the roots with chitosan polymer (CH), chitosan (COS) and pectic (OGAS) oligosaccharides and Spermine (Sp). All macromolecules tested activated protein levels and defense enzymatic activity in tobacco leaves but with different response dynamics among them and depending on the biochemical variable evaluated. Defense response above control levels were detected since 12 hours after treatments and it consisted in a biphasic behavior with two peaks for PAL (EC 4.3.1.5) and $\beta 1$ - 3 glucanase (EC 3.2.1.6) enzymatic activities. The highest enzymatic levels for these enzymes were achieved at 48 hours in plantlets elicited with COS and at 72 hours for those plants treated with chitosan polymer, while the highest POD (EC 1.11.1.6) activity was detected with $\mathrm{CH}$ between 48 and 72 hours. These results demonstrated systemic defense activation by oligosaccharins in tobacco whose dynamic of defense response is affected by the kind of oligosaccharins tested. When applying OGAS by foliar spray on tobacco, systemic resistance against Phytoththora nicotianae was induced and plantlets were protected 
with the low concentration tested by $46 \%$ under the bioassays conditions performed. Moreover, enzymatic determinations on roots and leaves previous to plant-pathogen interaction showed increments above $30 \%$ of control levels for PAL and POD activities. It means that oligosaccharins activate local and systemic defense responses in plants in the absent of pathogen infection.

\section{Keywords}

\section{Systemic Induced Resistance, Oligosaccharins, Tobacco, Defensive Enzymes}

\section{Introduction}

The cell wall is the forefront on plant-pathogen interactions. Cell wall from plants is the first barrier encountered by most pathogens; it must be degraded by them in order to allow penetration and colonization of internal tissues [1]. Therefore, it contains many substrates of pathogen enzymes and its degradation liberated various and different oligosaccharides fragments, several of which constitute first signals (elicitors) for inducing resistance in the plant [2] [3].

Pectins are one of the first targets of digestion by invading pathogens through pectinases enzymes. Oligogalacturonides are released when pectinases, as endopolygalacturonases and endopectatelyases, secreted by the pathogen degrade the homogalacturonan in the plant cell wall [1]. Oligogalacturonides released are a carbon source for the pathogens, but can also be detected by plants as signals to initiate defense responses [4] [5].

Among the first defensive responses triggered by plants, when their receptors detect the above mentioned elicitors, are the hydrolytic enzymes as $\beta 1$ - 3 glucanases and chitinases, able to degrade pathogen cell wall polymers [1]. These enzymes release oligosaccharides of glucans, chitins and chitosans, which are, in turn, perceived and transduced by the defensive machinery of the plant, causing an amplification of its resistance response against the pathogen [5]. Several of these oligosaccharides also activate growth and development responses in plants and they are known as oligosaccharins [3]-[5].

Pectic oligosaccharides have been implicated as signals for activating wide range of defense responses through its interaction with receptors of plant membrane and mediated by the octadecanoid and the salicylic acid accumulation pathways [2] [3] [6]. The size requirements in oligogalacturonides for inducing defense responses in plants are wide, but most of reports suggest a degree of polymerization between 9 to 16 as the most actives [4]. However, despite many defensive responses and secondary signals activated by oligogalacturonides are known, there are very few reports of actual plant protection in vivo against pathogens with these oligosaccharides [6].

In the last decade, a collaborative work among different research groups in the subject, have demonstrated the potential of chitosaccharides (poly and oligochitosans) in the activation of defense enzymes and resistance against the pathogen of tobacco Phytophthora nicotianae [7]-[9]; however, several questions still remains to be cleared, as for instance, it is not known the time behavior of defensive enzymes activated by oligosaccharins in plant organs far from the activation site.

This study provides evidences to answer the scientific questions outlined above. Firstly, the behavior of key plant defensive enzymes against pathogens was evaluated in a dynamic response study when tobacco plantlets were elicited by different oligosaccharins and plant organic compounds. In addition, it is shown how a defined mixture of pectic oligosaccharides can actually protect tobacco plants against the soilborne pathogen Phytophthora nicotianae by inducing plants' own defense mechanisms.

\section{Methods and Materials}

\subsection{Chemicals}

Three amino compounds were employed as elicitors of plant defenses in a bioassay: a chitosan (CH) polymer $(\mathrm{DA}=36.5 \%, \mathrm{DP}=794)$, an oligochitosan (COS) mixture (DA= 0\% $-1 \%, \mathrm{DP}=5-9)$ and Spermine (Sp) (Sigma). As elicitor of plant defense and resistance, it was also used a mixture of pectic oligosaccharides (OGAs) commercially known as Pectimorf and obtained by enzymatic degradation of pectic acid [10]. 


\subsection{Comparative Dynamic of Plant Defense Activation by Organic Elicitors}

Bioassay Procedure and Enzymatic Determinations

Tobacco plantlets of 26 days old were gently removed from substrate, the roots washed and plantlets placed through the roots in $0.5 \mathrm{~g} \cdot \mathrm{L}^{-1}$ of elicitors treatments (Chitosan polymer, chitosan oligosaccharides, pectic oligosaccharides and Spermine) following the procedure previously describe [8].

After one hour of treatment, plantlets were change to glass tubes containing Hoagland solution 10\% [11] applied through the roots for surviving until protein extractions. At different times $(0,12,24,48,72$ hours) true leaves from tobacco plantlets were collected from elicited plants and control, and extracted on a mortar and pestle under liquid nitrogen with the following buffer: AcNa 0.05 M + PVP (1\%) + Triton X-100 (0.25\%) + PMSF $1 \mathrm{mM}$ in a rate of $1 \mathrm{~g}$ per $1.5 \mathrm{~mL}$. The extracted was, then, centrifuged at $12,000 \mathrm{rpm}$ for 15 minutes at $4^{\circ} \mathrm{C}$. The supernatant was collected in microtubes and store at $-60^{\circ} \mathrm{C}$ until subsequent analysis.

Plant enzymatic activities [PAL (EC 4.3.1.5), POD (EC 1.11.1.6) and $\beta 1$ - 3 glucanase (EC 3.2.1.6)] and proteins were determined in the supernatant of leaf extracts following the same procedures previously described [8] [9]. At least three replicates were used by treatment and experiments were repeated twice.

In all the enzymatic determinations data were processed through a simple analysis of variance and the resulting means were compared by the Tukey test for $\mathrm{p}<0.05$ using the statistical program SPSS for Windows ${ }^{\circledR}$, version 11.5.

\subsection{Assessment of Tobacco Plant Protection by Induced Resistance with OGAS}

\subsubsection{Bioassay Procedure}

The experiment was carried out using tobacco plants of "Corojo" Cuban variety (susceptible to P. nicotianae) cultivated in a mixture of soil and organic matter $1: 1 \mathrm{v} / \mathrm{v}$ under semi-controlled conditions with a light/dark regime of $16 / 8$ hours and a temperature of $28^{\circ} \mathrm{C} / 23^{\circ} \mathrm{C}$, respectively.

Treatments were performed by applying two doses $\left(0.5,0.05 \mathrm{~g} \cdot \mathrm{L}^{-1}\right)$ of the oligogalacturonide mixture in $\mathrm{H}_{2} \mathrm{Od}$ as foliar spray. Tobacco plants of 35 days old (5 days after spraying) treated as stated before were gently removed from the substrate and placed in eppendorf tubes containing 50 times diluted nutrient solution [11] and an agar culture plug bearing mycelium of a pathogenic strain (227) of $P$. nicotianae placed at the bottom. This allowed contact between plant roots and pathogen mycelia [9] [12]. Plant pathogen interaction was allowed to proceed for 5 days before determining plant infection using a scale. As control, tobacco plantlets were sprayed with $\mathrm{H}_{2} \mathrm{Od}$.

\subsubsection{Processing of Plant Protection Data}

Infection degree was determined in each plant using the scale of five degrees (Table 1) of pathogen invasion previously described [12]. Fifteen plants by treatment were tested and experiments were repeated twice with similar results. Data were processed according to the Kruskal-Wallis non parametric test and all means compared in an independent way through the Mann-Whitney test for $\mathrm{p}<0.05$, by using the statistical program SPSS for Windows ${ }^{\odot}$, version 11.5. Results were presented as mean rank and percentage of plant infection compared to controls (100\% infection).

\subsubsection{Plant Proteins Extraction and Enzymatic Analysis}

The true leaves and roots from 35 days old plants treated by spraying (and no used in the pathogen bioassay) were collected 5 days after treatment and ground in a porcelain mortar and pestle in presence of liquid nitrogen.

Table 1. Scale of pathogen invasion in tobacco plants.

\begin{tabular}{cc}
\hline Degree & Description \\
\hline 1 & Healthy plant \\
2 & Roots affected \\
3 & Hypocotyls and cotyledons affected \\
4 & First and second leaves pair affected \\
5 & Dead plant \\
\hline
\end{tabular}


Powdered leaves and roots were extracted in $50 \mathrm{mM}$ sodium acetate buffer pH 5.2 containing $5 \mathrm{mM}$ EDTA, 14 $\mathrm{mM} \beta$-mercapto-ethanol and $1.0 \mathrm{M} \mathrm{NaCl}$ at the rate of $1 \mathrm{~g}$ per $2 \mathrm{ml}$ of buffer. The extract was then centrifuged at $12,000 \mathrm{~g}$ for 15 minutes at $4^{\circ} \mathrm{C}$ in a Sigma Microcentrifuge. The supernatant was collected in clean eppendorf tubes and stored at $-10^{\circ} \mathrm{C}$ for subsequent analysis. Enzymatic determinations were performed in the supernatant of leaf and roots extracts as described in the first experiment and according to [8] [9].

\section{Results}

\subsection{Comparative Dynamic of Plant Defense Activation by Organic Elicitors}

All macromolecules tested activated protein levels and defense enzymatic activity in tobacco leaves above the control, but with different response dynamics among them and depending on the biochemical variable tested. Protein increments above control treatment on tobacco leaves were detected since 12 hours after elicitor applications with all compounds evaluated (Figure 1). The highest increments occurred at 48 hours induced by COS elicitor and followed by OGAS induction. At 72 hours the highest increments were detected with the chitosan polymer $(\mathrm{CH})$ and the spermine $(\mathrm{Sp})$, which both triplicated the control level. These protein augment could be related to de novo synthesis of defensive proteins.

PAL enzymatic activity was induced above control in a biphasic response by the elicitors tested, although, differentially peaking for each one (Figure 2). The first peak was achieved at 12 hours after treatment with the amino compounds tested, while the second peak was higher than the first one at 48 hours for spermine and oligochitosans. Chitosan polymer peaked the second phase at 72 hours of treatment. OGAS just provoked a peak above control between 48 and 72 hours of treatment.

The dynamic behaviour of $\beta 1$ - 3 glucanase activity was about similar than PAL (Figure 3). A biphasic behaviour with the amino compounds and just one phase behaviour for OGAS elicitor, peaking at 48 hours with about two fold the control level. Chitosan polymer caused the highest increment above control in the first peak (more than three times), while the second peak at 48 hours was activated by COS, Sp and OGAS. The second peak duplicated the level of first one. Similarly to PAL enzymatic activity, the chitosan polymer provoked the second peak at 72 hours of treatment with an increment of $\beta 1$ - 3 glucanase activity almost three times above the control.

POD enzymatic activity was activated above control since 12 hours of treatments by COS, Sp and OGAS (Figure 4). For chitosan polymer, the activation above control started at 24 hours and rose to the double or

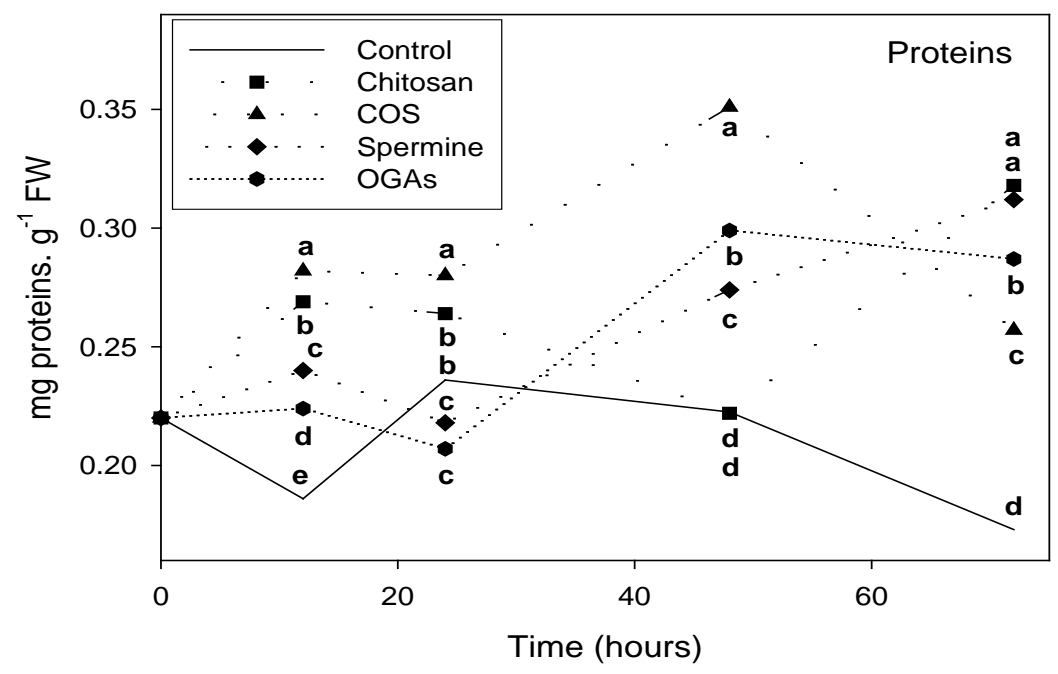

Figure 1. Time-course of soluble proteins contents in tobacco leaves from plants previously elicited with organic elicitors: Chitosan polymer, oligochitosans mixture (COS), Spermine and oligogalacturonide mixture (OGAS). Proteins were determined on leave extracts after 12, 24, 48 and 72 hours from root treatments. Different letters among treatments indicate significant differences in Tukey's Test ( $\mathrm{p} \leq$ 0.05). 


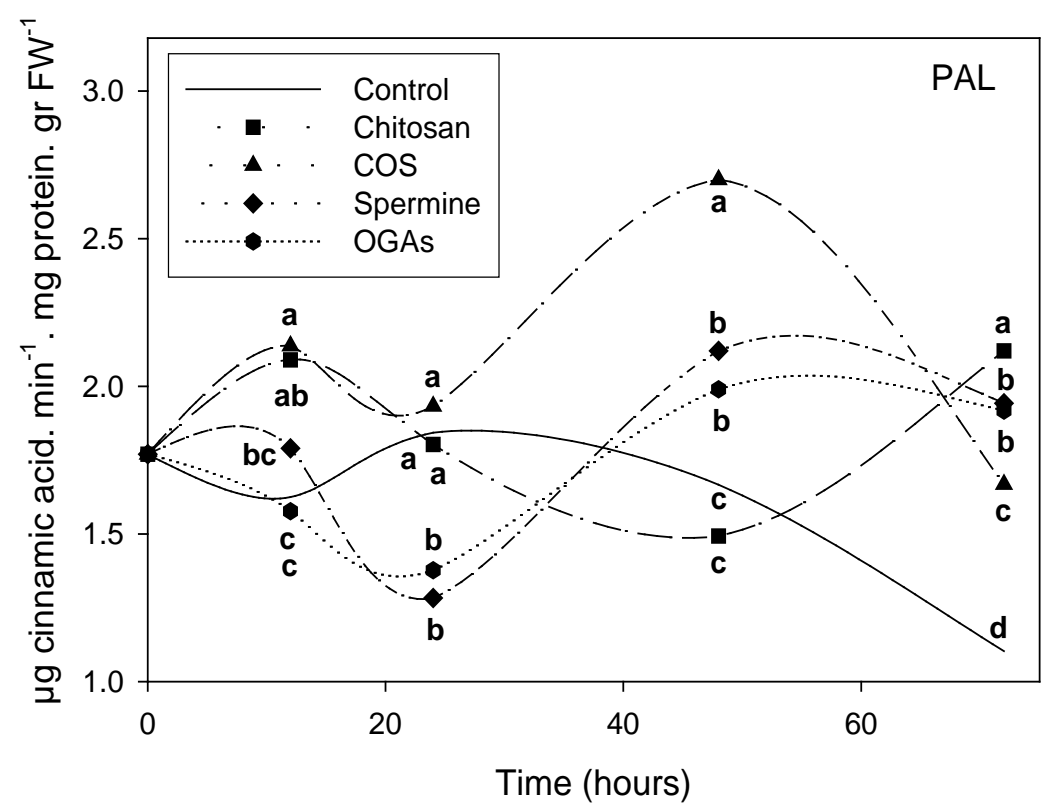

Figure 2. Time-course of PAL enzymatic activation in tobacco leaves from plants previously elicited with organic elicitors: Chitosan polymer, oligochitosans mixture (COS), Spermine and oligogalacturonide mixture (OGAS). Proteins were determined on leave extracts after 12, 24, 48 and 72 hours from root treatments. Different letters among treatments indicate significant differences in Tukey's Test ( $p \leq$ 0.05).

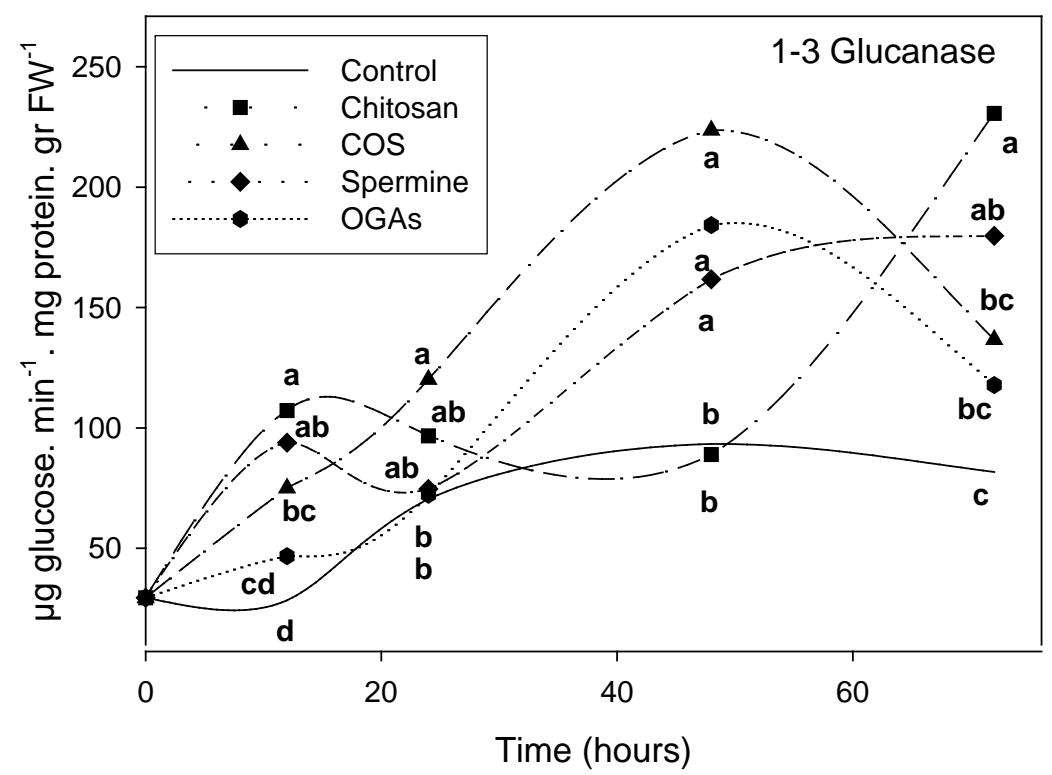

Figure 3. Time-course of $\beta$ 1-3 glucanase enzymatic activation in tobacco leaves from plants previously elicited with organic elicitors: Chitosan polymer, oligochitosans mixture (COS), Spermine and oligogalacturonide mixture (OGAS). Proteins were determined on leave extracts after 12,24 , 48 and 72 hours from root treatments. Different letters among treatments indicate significant differences in Tukey's Test $(\mathrm{p} \leq 0.05)$.

higher at 48 and 72 hours of treatment. At similar times, the other elicitors tested caused the same behaviour, under or a little above control level. 


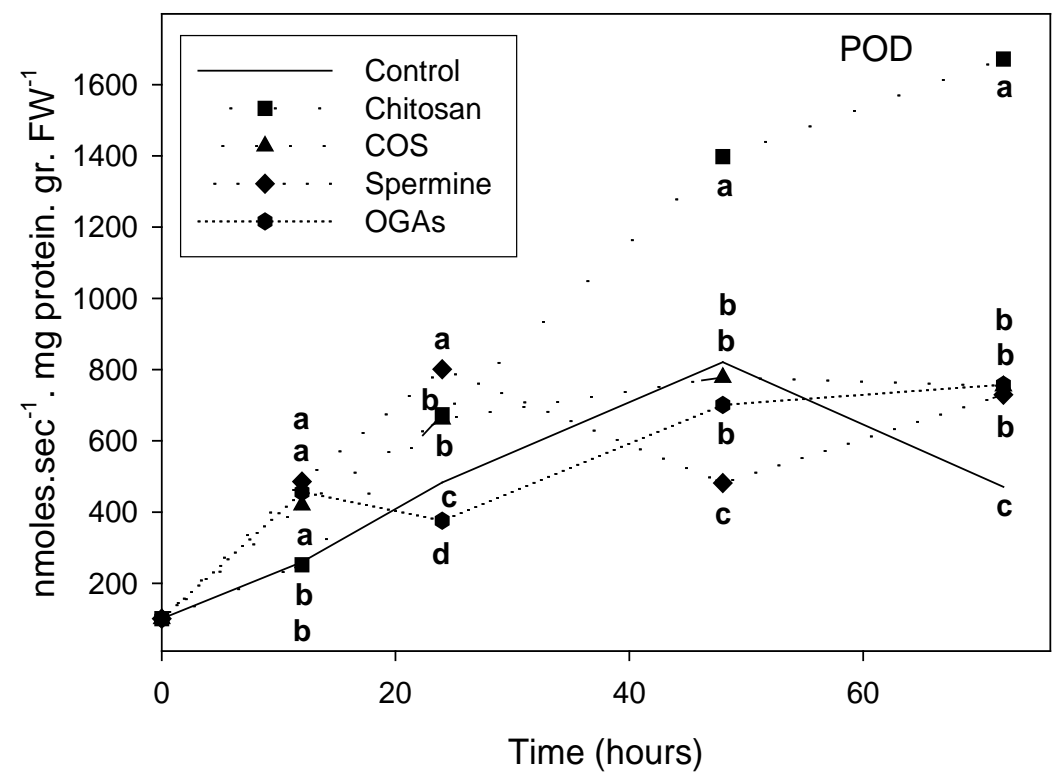

Figure 4. Time-course of peroxidase enzymatic activation in tobacco leaves from plants previously elicited with organic elicitors: Chitosan polymer, oligochitosans mixture (COS), Spermine and oligogalacturonide mixture (OGAS). Proteins were determined on leave extracts after 12, 24, 48 and 72 hours from root treatments. Different letters among treatments indicate significant differences in Tukey's Test $(\mathrm{p} \leq 0.05)$.

\subsection{Assessment of Tobacco Plant Protection by Induced Resistance with OGAS}

In order to test the capacity of eliciting of induced resistance by OGAS, it was performed a five days activation bioassay studied before [12]. Foliar spray of tobacco plantlets with a mixture of oligopectates caused reduction of infection index with both concentrations tested (Table 2). However, despite of the treatment with OGAS at $0.5 \mathrm{~g} \cdot \mathrm{L}^{-1}$, caused a reduction of $25 \%$ of the infection index, no significant differences were found with the control $100 \%$ infected. Conversely, the lowest OGAS concentration $\left(0.05 \mathrm{~g} \cdot \mathrm{L}^{-1}\right)$ tested, significantly reduced the infection index by $46 \%$.

Taking into account the bioassay performed, in which plants are sprayed in their aerial parts and the infection is carried out later on through the plant roots, it is possible to conclude that the protection observed is due to the induction of systemic resistance in tobacco plants by the oligogalacturonide mixture.

The OGAS mixture caused activation of PAL and POD activities in roots and leaves of tobacco plantlets. PAL enzymatic activity on leaves was significant increased above control by $30 \%$ with the low concentration tested, while the increment of PAL activity with the highest OGAS concentration neither differed from control nor the treatment with low OGAS concentration (Figure 5). On roots, both OGAS concentrations caused significant increments respect to control. The highest increment (31\%) of enzymatic activity was achieved with the high OGAS concentration tested with no difference with the low OGAS concentration tested.

For POD enzymatic activity the behaviour was similar to the PAL on roots but different on leaves. On leaves, the highest increment of enzymatic activity was activated by the high OGAS concentrations tested with significant difference regarding to the control and the low OGAS concentration tested (Figure 6). The highest increment above control on leaves was of $40 \%$ while on roots it was about $30 \%$.

\section{Discussion}

Generally speaking, the results from the first experiment performed demonstrated that the organic compounds tested in this work activated systemic induced resistance in tobacco plants since, the enzymatic defences, related to induced resistance, were activated on plant leaves above control levels following several hours that roots had been treated. By first time, it was evaluated the systemic behaviour on time of protein and defence enzymes activation by these compounds in tobacco leaves. 
Table 2. Activation of induced resistance in tobacco plants (Nicotiana tabacum var. Corojo) against Phytophthora nicotianae by an oligopectates mixture (OGAS). Treatments were applied as foliar spray when plants were 30 days old. Data were processed according to the Kruskal-Wallis non parametric test and all means compared in an independent way through the Mann-Whitney test for $\mathrm{p}<0.05$, by using the statistical program SPSS for Windows ${ }^{\odot}$, version 11.5.

\begin{tabular}{cccc}
\hline Treatments & N & Means of Ranks & \% of Infection \\
\hline Control & 15 & $30.87 \mathrm{a}$ & 100 \\
OGAS $0.05 \mathrm{~g} \cdot \mathrm{L}^{-1}$ & 16 & $16.94 \mathrm{~b}$ & 53.65 \\
OGAS $0.5 \mathrm{~g} \cdot \mathrm{L}^{-1}$ & 15 & $23.13 \mathrm{ab}$ & 74.7 \\
\hline
\end{tabular}

$$
\mathrm{X}^{2}=12.08^{* * *} \text {. }
$$

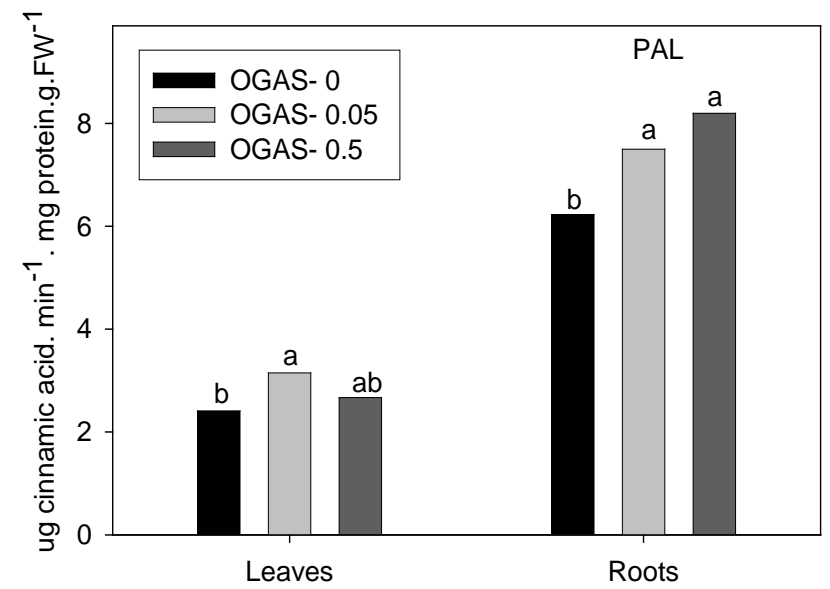

Figure 5. Changes in PAL enzymatic activity in leaves (SEx $=0.12)$ and roots (SEx $=0.23)$ of 35-day-old tobacco plants elicited with two concentrations of the oligopectates mixture (OGAS). Treatments were performed as foliar spray 5 days before roots and leaves extraction. Different letters among treatments indicate significant differences in Tukey's Test ( $p \leq 0.05)$.

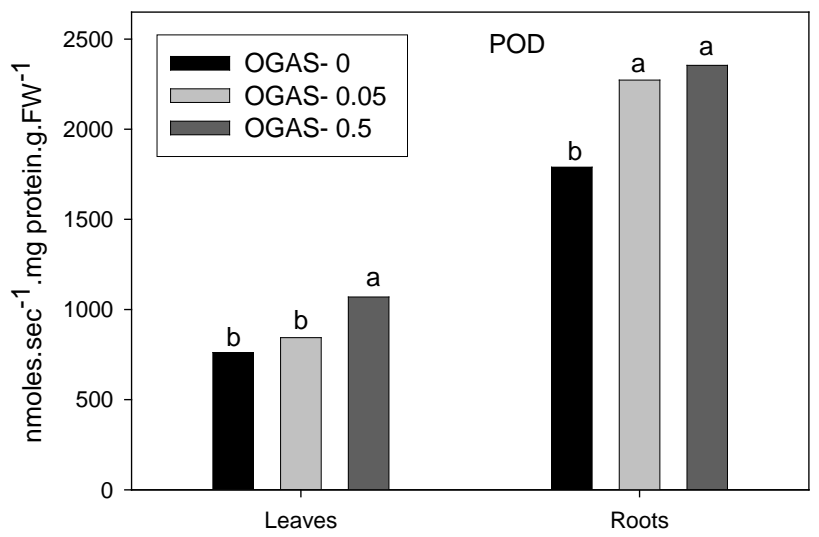

Figure 6. Changes in POD enzymatic activity in roots (SEx = 84.9) and leaves (SEx = 33.42) of 35-day-old tobacco plants elicited with two concentrations of the oligopectates mixture (OGAS). Treatments were performed as spray 5 days before roots and leaves extraction. Different letters among treatments indicate significant differences in Tukey's Test $(p \leq 0.05)$.

The defence activation followed different behaviours depending on time for determination and the type of compound tested. According to results, biphasic behaviour was detected on variables evaluated, except for POD where, it was not clearly appreciated. Firstly, a lower first peak occurred at 12 hours after treatment, while a two or three times higher second peak could be detected at 48 or 72 hours after treatments and depending on the type of compound tested.

Former studies stated that induced resistance at cell level consist in, at least, two moments of defence activation, an early response, where a smaller number of defence genes which are related to the recognition and a first defensive barrier against the pathogen are activated. They are also involved on the amplification and signalling 
of the response expressed. In addition, a second array of similar and new synthetized defence responses is activated, causing the amplification of the whole plant resistance against pathogen [13]-[15]. Depending on the level of analysis (protoplast, cells, tissues, organs or plants) this process delay from seconds to days. From our results this process could be happened between 12 and 72 hours as a systemic response in a whole tobacco plant. Former works from this lab demonstrated tobacco protection by induced resistance against a pathogen, when plantlets were treated with chitosaccharides, at least, 72 hours before established the infection process [9] [12].

With these and previous results [9], the criterion for the occurrence of generalized defense activation in plants by oligosaccharins, even in the absence of pathogens, which is not always the response in plants for other defensive elicitors, is confirmed [16] [17]. In the next future, it could be interesting to study the behavior of these defense enzymes during the infection process in plants elicited with oligosaccharins.

All three enzymes evaluated in this study were, differentially, time activated on tobacco leaves depending on the elicitor structure type. From results, main differences for the highest peak of activity occurred, apparently, as a result of the influence of elicitor molecular weight, since, the protein contents and the enzymatic activities achieved the highest level with lower molecular weight elicitors (COS, OGAS and Spermine) about 48 hours after treatment, while for the chitosan polymer (high molecular weight) the highest increments occurred at 72 hours after treatment. Therefore, it is possible that different behaviour because of molecular weight be related with the perception at membrane level, since; low molecular weight compounds can pass easier plant coverts and wall cell to achieve receptors in membrane. Conversely, chitosan polymer must delay to achieve the membrane because of its polymeric structure and, probably, it could be hydrolysed by enzymes with chitosanolytic activities which are free located at the level of cell wall and apoplast [18]. Additionally, former authors speculated about different perceptions for polymeric and oligomeric chitosan derivatives. Apparently, oligochitosans are perceived through protein receptors in plant membrane, while perception of polymeric derivatives is through electrostatic interactions with negatively charged membrane phospholipids exposed to the apoplast [19].

In general, oligogalacturonide mixture induced less enzymatic activity than amino compounds; even, the biphasic enzymatic behaviour was much less clearly appreciated with OGAS than with the other elicitors evaluated. This could be the reason why the tobacco protection obtained against $P$. nicotianae was less effective with the same concentration $\left(0.5 \mathrm{~g} \cdot \mathrm{L}^{-1}\right)$ tested. Since low OGAS concentration caused higher protection, it is necessary in the next future to evaluate an experiment of dose-protection for this mixture.

Enzymatic increments on roots and leaves were not higher than $30 \%$ respect to control. This value is not so high compare to increments previously found, by using the same bioassay but, with chitosan derivatives as elicitors [8] [9]. PAL, although it does not have antimicrobial activity per se, is a key enzyme from which diverge microbial metabolic pathways that produce structures such as chlorogenic acid, and chemical barriers such as lignin. However, PAL which is considered a key defence in tobacco against this pathogen, when using this type of application [9] [15] did not increase so much above control compare to previous report using the same mode of application of chitosan derivatives [9].

As conclusion, this work demonstrated systemic activation of important tobacco defence markers by oligosaccharins and confirming this defence induction in the absent of pathogen infection. As novelty, it was shown the capability of OGAS to protect tobacco plantlets against its main soilborne pathogen at nursery stage. In addition, it was shown the defence enzymatic activation on tobacco leaves and roots by oligogalacturonide treatments. In order to appreciate the practical value of this work, next experiments with plant-pathogen interaction must be performed closer to the regular plantlets development on tobacco nurseries.

\section{Acknowledgements}

First author wants to thank the financial support to the research included in this publication by Conacyt (Mexico) and the International Foundation for Science (Project F-4446-2F). Thanks to Q. B. Francisco Soto and Q. B. Socorro Vallejo (CIAD) for their technical assistance.

\section{References}

[1] Esquerré-Tugayé, M.-T., Boudart, G. and Dumas, B. (2000) Cell Wall Degrading Enzymes, Inhibitory Proteins and Oligosaccharides Participate in the Molecular Dialogue between Plants and Pathogen. Plant Physiology and Biochemistry, 38, 157-163. http://dx.doi.org/10.1016/S0981-9428(00)00161-3

[2] Vorwerk, S., Somerville, S. and Somerville, C. (2004) The Role of Plant Cell Wall Polysaccharide Composition in 
Plant Disease Resistance. Trends Plant Sciences, 9, 203-209. http://dx.doi.org/10.1016/j.tplants.2004.02.005

[3] Courtois, J. (2009) Oligosaccharides from Land Plants and Algae: Production and Applications in Therapeutics and Biotechnology. Current Opinion in Microbiology, 12, 261-273. http://dx.doi.org/10.1016/j.mib.2009.04.007

[4] Ridley, B.L., O’Neill, M.A. and Mohnen, D. (2001) Pectins: Structure, Biosynthesis, and Oligogalacturonide-Related Signaling. Phytochemistry, 57, 929-967. http://dx.doi.org/10.1016/S0031-9422(01)00113-3

[5] Shibuya, N. and Minami, E. (2001) Oligosaccharide Signalling for Defense Responses in Plant. Physiological and Molecular Plant Pathology, 59, 223-233. http://dx.doi.org/10.1006/pmpp.2001.0364

[6] Aziz, A., Heyraud, A. and Lambert, B. (2004) Oligogalacturonide Signal Transduction, Induction of Defense-Related Responses and Protection of Grapevine against Botrytis cinerea. Planta, 218, 767-774. http://dx.doi.org/10.1007/s00425-003-1153-x

[7] Falcón-Rodríguez, A.B., Costales-Menéndez, D., Ortega-Delgado, E., León-Díaz, O., Cabrera-Pino, J.C. and MartínezTéllez, M.A. (2007) Evaluation of Chitosan as Inhibitor of Soilborne Pathogens and Elicitor of Defence Markers and Resistance in Tobacco Plants. Spanish Journal of Agricultural Research, 5, 533-541. http://dx.doi.org/10.5424/sjar/2007054-274

[8] Falcón-Rodríguez, A.B., Cabrera, J.C., Ortega, E. and Martínez-Téllez, M.A. (2009) Concentration and Physico-Chemical Properties of Chitosan Derivatives Determine the Induction of Defense Responses in Roots and Leaves of Tobacco (Nicotianatabacum) Plants. American Journal of Agricultural and Biological Sciences, 4, 192-200. http://dx.doi.org/10.3844/ajabssp.2009.192.200

[9] Falcón-Rodríguez, A.B., Costales, D., Cabrera, J.C. and Martínez-Téllez, M.A. (2011) Chitosan Physic-Chemical Properties Modulate Defense Responses and Resistance in Tobacco Plants against the Oomycete Phytophthora nicotianae. Pesticide Biochemistry and Physiology, 100, 221-228. http://dx.doi.org/10.1016/j.pestbp.2011.04.005

[10] Cabrera, J.C., Gómez, R., Diosdado, E., Hormaza, J., Iglesias, R. Gutiérrez, A. and González, S. (2003) Procedure to Obtain a Pectic Oligosaccharide Mixture with Plant Rooting Activity. Cuban Patent No. 22859, Resolution 155/2003.

[11] Hoagland, D.R. and Arnon, D.I. (1950) The Water Culture Method of Growing Plants without Soil. California Agricultural Experimental Station, Circ 347.

[12] Falcón, A.B., Cabrera, J.C., Costales, D., Ramírez, M.A., Cabrera, G., Toledo, V. and Martínez-Téllez, M.A. (2008) The Effect of Size and Acetylation Degree of Chitosan Derivatives on Tobacco Plant Protection against Phytophthora parasitica nicotianae. World Journal Microbiology and Biotechnology, 24, 103-112. http://dx.doi.org/10.1007/s11274-007-9445-0

[13] van Loon, L.C., Rep, M. and Pieterse, C.M.J. (2006) Significance of Inducible Defense-Related Proteins in Infected plants. Annual Review of Phytopathology, 44, 135-162. http://dx.doi.org/10.1146/annurev.phyto.44.070505.143425

[14] Garcia-Brugger, A., Lamotte, O., Vandelle, E., Bourque, S., Lecourieux, D., Poinssot, B., Wendehenne, D. and Pugin, A. (2006) Early Signaling Events Induced by Elicitors of Plant Defenses. Molecular Plant-Microbe Interaction, 19, 711-724. http://dx.doi.org/10.1094/MPMI-19-0711

[15] Desender, S., Andrivon, D. and Val, F. (2007) Activation of Defense Reactions in Solanaceae: Where Is the Specificity? Cellular Microbiology, 9, 21-30. http://dx.doi.org/10.1111/j.1462-5822.2006.00831.x

[16] Heil, M. and Bostock, R. (2002) Induced Systemic Resistance (ISR) against Pathogens in the Context of Induced Plant Defenses. Annual of Botany, 89, 503-512. http://dx.doi.org/10.1093/aob/mcf076

[17] Heil, M. and Walters, D. R. (2009) Ecological Consequences of Plant Defence Signalling. In: van Loon, L.C., Ed., Advances in Botanical Research, Vol. 51, Academic Press, Burlington, 667-716.

[18] Grenier, J. and Asselin, A. (1990) Some Pathogenesis-Related Proteins Are Chitosanases with Lytic Activity against Fungal Spores. Molecular Plant-Microbe Interaction, 3, 401-407. http://dx.doi.org/10.1094/MPMI-3-401

[19] Vander, P., Varum, K.M., Domard, A., El Gueddari, N.E. and Moerschbacher, B.M. (1998) Comparison of the Ability of Partially N-Acetylated Chitosans and Chitooligosaccharides to Elicit Resistance Reactions in Wheat Leaves. Plant Physiology, 118, 1353-1359. http://dx.doi.org/10.1104/pp.118.4.1353 


\section{Abbreviations Used}

DA: degree of acetylation;

DP: degree of polymerization;

$\mathrm{CH}$ : chitosan polymer;

COS: oligochitosans;

OGAS: oligogalacturonides or oligopectates;

Sp: spermine;

PAL: phenyl-alanine ammonia lyase;

POD: peroxidase;

PMSF: phenyl-methyl sulfonyl fluoride. 
Scientific Research Publishing (SCIRP) is one of the largest Open Access journal publishers. It is currently publishing more than 200 open access, online, peer-reviewed journals covering a wide range of academic disciplines. SCIRP serves the worldwide academic communities and contributes to the progress and application of science with its publication.

Other selected journals from SCIRP are listed as below. Submit your manuscript to us via either submit@scirp.org or Online Submission Portal.
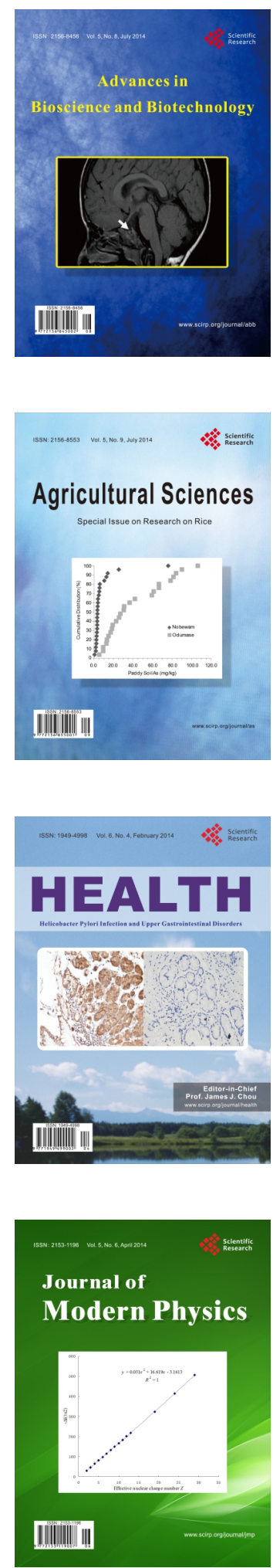
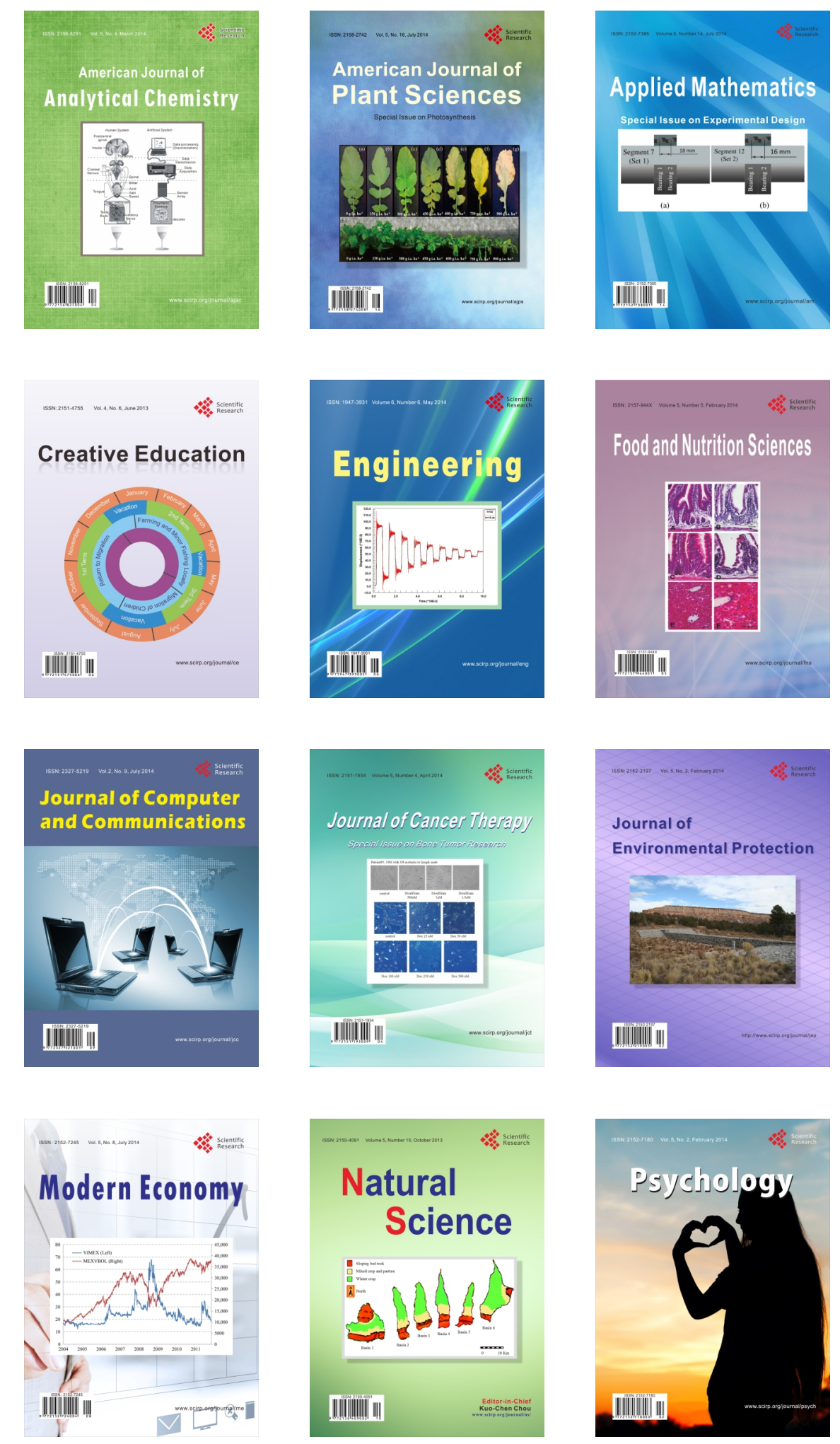